\title{
Building Computational Creativity in an Online Course for Non-Majors
}

\author{
Markeya S. Peteranetz \\ Dept. of Computer Science and Engineering \\ University of Nebraska-Lincoln \\ 256 Avery Hall, Lincoln, NE 68588-0115 \\ markeya.dubbs@huskers.unl.edu
}

\author{
Leen-Kiat Soh \\ Dept. of Computer Science and Engineering \\ University of Nebraska-Lincoln \\ 256 Avery Hall, Lincoln, NE 68588-0115 \\ lksoh@cse.unl.edu
}

\author{
Elizabeth Ingraham \\ School of Art, Art History \& Design \\ University of Nebraska-Lincoln \\ 120 Richards Hall, Lincoln, NE 68588 \\ eingraham2@unl.edu
}

\begin{abstract}
In recent years, a growing number of universities have begun to offer specialized courses as a way to make computer science (CS) more accessible to students with little or no prior CS or programming experience, especially non-CS majors. One of the ways courses have been modified for these students is by supplementing the core problem solving and coding aspects of the curriculum with explicit instruction on computational thinking principles. These "computational thinking" courses are promising in that they ground computational thinking in discipline-specific contexts and emphasize application of computational principles. However, there is little empirical research evaluating the extent to which students learn computational thinking from these courses. The purpose of this study was to evaluate the impact of an online Computational Creativity course on students' computational thinking skills, creative competencies, and self-efficacy. Students in the Computational Creativity course were predominantly non-CS majors, and they completed four Computational Creativity Exercises (CCEs) that have previously been shown to improve learning and achievement. Results indicate that the Computational Creativity course was effective in increasing students' computational thinking knowledge and self-efficacy for applying computational thinking in their fields, but it did not have an impact on students' creative competencies. Additionally, students' reactions to the course and the CCEs were mostly positive. Thus, this study provides initial evidence that non-CS majors can learn computational thinking through the online Computational Creativity course.
\end{abstract}

\section{CCS CONCEPTS}

- Social and professional topics Computational thinking • Applied computing Collaborative learning • Applied computing E-learning

\footnotetext{
Permission to make digital or hard copies of all or part of this work for personal or classroom use is granted without fee provided that copies are not made or distributed for profit or commercial advantage and that copies bear this notice and the full citation on the first page. Copyrights for components of this work owned by others than ACM must be honored. Abstracting with credit is permitted. To copy otherwise, or republish, to post on servers or to redistribute to lists, requires prior specific permission and/or a fee. Request permissions from Permissions@acm.org.

SIGCSE'19, February 27-March 2, 2019, Minneapolis, MN, USA.

(c) 2019 Association of Computing Machinery.

ACM ISBN 978-1-4503-5890-3/19/02..\$15.00

https://doi.org/10.1145/3287324.3287346
}

\section{KEYWORDS}

Collaborative learning; Computational thinking; Computational creativity; Creativity; Non-majors

\section{ACM Reference format:}

Markeya S. Peteranetz, Leen-Kiat Soh, and Elizabeth Ingraham. 2019. Building computational creativity in an online course for non-majors. In Proceedings of the 50th ACM Technical Symposium on Computing Science Education (SIGCSE '19). February 27-March 2, 2019, Minneapolis, MN, USA ACM, New York, NY. https://doi.org/10.1145/3287324.3287346

\section{Introduction}

Online courses have come to be a common part of post-secondary education in the United States. Some degree programs are entirely online, and colleges are offering an increasing number of courses online. This trend is also present in computer science (CS) and computing education, and as a result there is interest in determining how effectively computational thinking skills can be taught through an online course. Though much has been written about the creation and implementation of online courses, especially Massive Open Online Courses (MOOCs), few studies have examined the effectiveness of teaching $\mathrm{CS}$ and computational thinking in an online format.

Early research on the effectiveness of teaching CS online yielded mixed results [1,2]. More recent research has shown students' test performance is comparable when CS classes are taught inperson or online [3]. Research in other disciplines [4-6] has also shown either equivalent performance across instructional formats or slightly better performance in online classes. When results show comparable outcomes in online and face-to-face courses, the conclusions about the effectiveness of online learning tend to differ based on whether the question of interest is, "can online instruction lead to better learning outcomes than face-to-face instruction?" or, "do the two methods yield equivalent outcomes?" In the former case, the idea is that online learning might be a solution to low achievement. In the latter case, the hope is that the administrative and monetary benefits of online instruction do not come at the expense of student learning. And, if the hope is that online instruction results in similar achievement, research show- 
ing no difference between the two methods, such as [3], gives reason to be optimistic about the wider adoption of online instruction.

The purpose of this study was to evaluate the impact of an online Computational Creativity course on students' computational thinking skills [7], creative competencies [8,9], and self-efficacy [10]. Students (who were predominantly not CS majors) enrolled in and completed a semester-long Computational Creativity course that was offered through the university's School of Art, Art History \& Design.

The following sections review research related to teaching computational thinking and CS through online courses and teaching computational thinking and CS to non-CS majors, followed by a discussion of computational creativity and exercises that can be used to incorporate it into classrooms. Then, the design and results of the study investigating the impact of the Computational Creativity course are presented. Finally, the results of the study are discussed.

\section{Related Research}

\subsection{Teaching Computer Science to Non-CS Ma- jors}

As the interdisciplinary potential of CS has come to be recognized more widely, colleges and universities have begun to offer CS courses specifically designed for students outside the CS major. For example, discipline-specific variations of CS were created through an "Applied Computer Science option" at Winona State University [11]. The applied option had separate tracks for students in bioinformatics, computer information systems, geographic information technology, and human computer interaction. Similarly, [12] outlined the design and evaluation of a CS1 course for science majors. The course took a "breadth-first" approach in order to familiarize students with as many topics as possible and taught the basics of programming in Python. Cortina [13] described a Principles of Computing course that was designed for non-technical non-CS majors. The course provided students an introduction to computing topics and the field of computer science separate from programming.

Soh et al. [14] went a step further and envisioned a suite of CS1 courses that integrated core CS curriculum with computational thinking rooted in a wide range of disciplines: engineering, the sciences, the arts, and humanities. In these courses, the same core CS1 content was taught, but the programming language, assignments, and lab activities were selected to be especially relevant for the different disciplines targeted by each class. This specialization and connection to different disciplines was intended to make the content more meaningful for students and also to make clearer the ways in which the knowledge and skills learned in the course could be applied to each discipline.

\subsection{Computational Thinking Courses}

The increased awareness of the interdisciplinary potential of CS and computational thinking has also led to attempts to reach nonCS majors through introductory computational thinking courses. For example, faculty at Purdue University developed a computational thinking course specifically for students majoring in a varie- ty of science programs including physics, chemistry, and biology [15]. At Tuskegee University, an introductory bioinformatics course was designed specifically to foster biology students' computational thinking [16]. However, as recently as 2015, Czerkawski and Lyman [17] observed "There is not yet a coherent crossinstitutional movement to incorporate [computational thinking] as a fundamental skill-set, outside of computer science and a few STEM disciplines." That is, although some institutions are taking steps to teach computational thinking to students outside of CS, non-CS computational thinking courses are still the exception rather than the rule.

One feature common to most computational thinking courses is a focus on grounding computational thinking principles and learning activities in a context that is familiar to most students. Often, making computational thinking familiar and accessible involves either eliminating or greatly reducing the presence of computer code in the curriculum. Czerkawski and Lyman [17] argued, "Engaging humanities and fine-arts majors in computational thinking projects requires field-appropriate introduction to [computational thinking] principles. ...focused on algorithms and principles of computational thinking without requiring any actual programming." Teaching computational thinking without code reduces the cognitive load [18] placed on students as they attempt to understand and apply computational thinking principles, and as a result, should make it easier for students without CS or coding experience to learning computational thinking.

Despite the reported instances of computational thinking courses being taught to non-CS majors (e.g., $[15,16])$, there is little available empirical research evaluating these courses. In one of the few cases where the course was evaluated, Chowdhury et al. [19] found that students had mostly positive experiences in the course and found the use of a collaborative cohort model to be beneficial. However, their evaluation focused on students' perceptions of and experiences with the course, it and did not include an analysis of students' learning of computational thinking. Thus, one goal of this study was to conduct a broad evaluation of the effectiveness of a computational thinking course for non-CS majors by examining students' learning and self-efficacy in addition to their perceptions of the course.

\subsection{Computational Creativity}

A novel way to teach computational thinking to non-CS majors (as well as CS students) is through computational creativity [20]. Computational creativity is the synergistic combination of computational thinking and creative thinking that can lead to more effective problem solving across disciplines and contexts. It takes the structure and versatility of computational thinking and infuses it with the flexibility and ingenuity of creative thinking. A computational creativity approach can be used to make computational thinking more accessible to students without CS or programming experience. In the computational creativity framework put forth by [20-23], the core components of computational thinking are abstraction, algorithm design, evaluation, generalization, pattern recognition, and problem decomposition [7], and creative thinking is rooted in Epstein's [8,9] creative competencies: Broadening, Capturing, Challenging, and Surrounding. 
Computational creativity is reflected in the integration of CS and the fine arts in the Performamatics courses developed at the University of Massachusetts Lowell [24]. In these courses, computational thinking and creative thinking were combined as students used computers and coding as the medium through which they created art or music. For example, in the Sound Thinking course, students learned how computational concepts such as algorithms, loops, and modularization are part of digitally composing music and performed music using Scratch. By highlighting the intersection of computation and music, the Sound Thinking course offers an entry point into CS for students who might not otherwise be interested in learning about CS or computational thinking.

2.3.1 Computational Creativity Exercises. Computational Creativity Exercises (CCEs) have been created specifically as a vehicle for introducing computational creativity into courses both in and outside of CS. As discussed in [20,23], the principles underlying the design of the CCEs are (1) balancing of attributes between computational and creative thinking and (2) mapping between computational and creative concepts and skills as they manifest in different disciplines. A brief description of the CCEs is provided next, and the reader is referred to [20-22] for more detail.

Each exercise has four basic components: (1) Objectives, (2) Tasks, (3) CS Light Bulbs, and (4) Questions. Each exercise is presented and completed on an online collaborative wiki platform, which is available within most Learning Management Systems (LMS). For each CCE, the objectives include a set of creative objectives, computational objectives, and collaborative objectives. Creative objectives are based on Epstein's four competencies: capturing, challenging, broadening, and surrounding. Computational objectives include two aspects: CS concepts, such as sorting and logical conditionals, and computational thinking skills, such as problem decomposition and abstraction. The collaborative nature of the CCEs facilitates creative thinking by bringing together students from diverse backgrounds. These objectives help students contextualize the purpose of the exercises by showing how an exercise lacking any programming code is related to CS concepts and by also indicating how students can use relevant creative thinking skills to complete the exercises.

The Task component lists all the tasks the group must complete during the two weeks of the exercise. Tasks require collaboration among the students and some require individual contributions. The CS Light Bulbs are text boxes embedded within the exercise handout that explicitly connect the task activities and CS topics specific to each participating course. The Light Bulbs help students relate what they do for the exercise to real-world issues and practices that utilize computational thinking and CS concepts. The Questions component presents open-ended questions that require students to reflect on their solutions and analyze potential issues with their solutions, encouraging them to evaluate the results of their original tasks using computational thinking and imagine further improvements using creative thinking.

Prior research [22-23,25-26] has demonstrated the effectiveness of CCEs in improving undergraduate students' learning and achievement. Positive effects have been found for students in introductory [22-23,27] and upper-level [21,25] courses, for CS majors and non-CS majors [23], and for engineering students in in- troductory CS [26,27]. Although CCEs have been shown to improve computational thinking knowledge in CS courses, studies have not shown an impact on CS students' creative competencies [21,25]. Additionally, all studies of the CCEs impacts on learning and achievement have been conducted in CS courses, where the CCEs were used to supplement to standard CS and programming instruction. That is, the CCEs have been shown to increase computational thinking knowledge and skills alongside the standard CS curriculum. The effectiveness of CCEs in building computational thinking separate from CS curriculum, such as in a computational thinking course designed for non-CS majors, has yet to be investigated.

\section{Research Questions and Hypotheses}

In this study, we investigated the following research questions:

Research Question 1: Did students' computational thinking knowledge and skills increase after taking the Computational Creativity course?

Hypothesis 1: Students' computational thinking knowledge and skills would increase after taking the Computational Creativity course.

Research Question 2: Did students' creative competencies increase after taking the Computational Creativity course?

Hypothesis 2: Students' creative competencies would not be changed by the Computational Creativity course. As previous stated, prior research has found no impact of CCEs on creative competencies, and therefore, we did not expect the Computational Creativity course to have an impact on students' creative competencies.

Research Question 3: Did students' self-efficacy for applying computational thinking increase after taking the Computational Creativity course?

Hypothesis 3: Students' self-efficacy would increase after taking the Computational Creativity course.

Research Question 4: How did students feel about the Computational Creativity course?

Due to the exploratory nature of this research question, no hypotheses were specified.

\section{Method}

This section contains descriptions of the Computational Creativity course, the participants in the study, and the instruments used.

\subsection{Course and Context}

We developed the Computational Creativity course to make computational thinking and creativity accessible and applicable for a broad range of students. It was partially adapted from a previously developed course that was delivered in a traditional in-person lecture format. Both the in-person course and the online course were 3 -credit hour courses, which is most common at this university. The course consisted of 6 modules. Each module centered on a set of ideas (e.g., "Module 4: Identifying creative blocks and applying creative blockbusters. Using your whole brain and managing time and stress."). They contained video-recorded lectures, discussion activities, and graded assignments. Four of the 6 modules contained a CCE, and the last 3 modules had assignments that were steps towards completing the final project. Students worked in groups for the CCEs, but all other activities were completed individually. The 4 CCEs used in this course were Exploring, Thinking 
Inside the Box, Storytelling, and Everyday Object. An extended description of Everyday Object is provided by [23].

\subsection{Participants}

During the fall 2017 semester, 42 students were enrolled in the Computational Creativity course, and 37 students (15 male, $22 \mathrm{fe}$ male; 13 freshman, 5 sophomore, 4 junior, 12 senior, 3 graduate/other) consented to participate and completed the beginningof-semester survey. The middle-of-semester survey was completed by 25 students, and the end-of-semester survey was completed by 27 students. Surveys were completed voluntarily and accessed via a web link provided by the course instructor. Survey and responses were only accessed by the researchers.

\subsection{Materials}

Students completed a battery of instruments via web-based survey at the beginning, middle, and end of the semester. Instruments measured students' computational thinking skills, motivation, selfregulation tendencies, affective reactions to the course, and perceptions of the CCEs. Only the instruments that are used in the present study are described here.

4.3.1 Computational Thinking Test. An 18-item test of computational thinking knowledge and skills was administered at the beginning and end of the semester. Items pertained to abstraction, algorithm design, evaluation, generalization, pattern recognition, and problem decomposition, with each dimension being represented by three items. Test items were written by a member of the research team who has expertise in computational thinking. Item analysis was conducted on both sets of test items, and the removal of sub-optimal items resulted in a 16-item subset that was used for analysis. Participants' scores were the total number of correct responses out of 16 (coefficient alpha: pre-test $=.72$, post-test $=.78$ ).

4.3.2 Creative Competencies Scale. Creative competencies were measured with a researcher-developed instrument adapted from the Epstein Creative Competencies Inventory (ECCI) [29]. The scale consisted of 4 items, and the score used for analysis was the mean of the items (coefficient alpha: beginning $=.65$, end $=.79$ ).

4.3.3 Self-Efficacy Scale. Participants' self-efficacy was measured at all three time-points by asking them to rate their confidence in their ability to apply computational thinking in their field ("Your ability to use computational algorithms to solve problems in your field,") [30]. Ratings were done on a scale from 0 (Completely Unconfident) to 100 (Completely Confident). The self-efficacy score was the mean of the items (coefficient alpha: beginning $=.92$, middle $=.96$, end $=.88$ ).

4.3.4 Course and CCE Ratings. As part of the end-of-semester survey, participants were asked to provide ratings for various aspects of the course and the CCEs. Ratings pertained to perceived "effectiveness," "usefulness," and "interestingness" of various aspects. For the effectiveness rating items the response scale was $1=$ not effective, 2 = neither effective nor ineffective, 3 = somewhat effective, 4 = effective, 5 = very effective, and for the usefulness and interestingness rating items the response scale was $1=$ very unuseful/uninteresting, 2 = unuseful/uninteresting, 3 = somewhat unuseful/uninteresting, $4=$ somewhat useful/interesting, $5=$ useful/interesting, 6 = very useful/interesting.

\section{Results}

The results of the four research questions are presented next. Paired-samples t-tests were used to answer Questions 1 and 2. Repeated-measures analysis of variance (ANOVA) was used to answer Question 3. Descriptive statistics were used to answer Question 4.

\subsection{Research Question 1: Did Students' Compu- tational Thinking Knowledge and Skills In- crease After Taking the Computational Creativity Course?}

The comparison of pre-test and post-test performance was based on the scores of participants who completed both tests. A student who had one of the highest scores on the pre-test and one of the lowest scores on the post-test was determined to be an outlier and was therefore excluded from the analysis of computational thinking test scores. The removal of the outlier resulted in an analysis sample of 23 participants.

Change in Computational Thinking test scores from the beginning to the end of the semester was tested with a paired samples $t$ test. There was a significant increase in scores from the beginning to the end of the semester $(t(22)=2.106, p=.047, D=0.41)$. This effect is medium according to the conventional interpretation of Cohen's D. Students' average score was 6.96 at the start of the semester and 8.30 at the end of the semester. This finding supports the hypothesis that test scores would increase for students who completed the Computational Creativity course. The positive effect suggests the online Computational Creativity course can be used to teach computational thinking knowledge and skills to nonCS students.

\subsection{Research Question 2: Did Students' Creative Competencies Increase After Taking the Computational Creativity Course?}

Change in students' creative competencies from the beginning to the end of the semester was tested with a paired samples $t$-test. There was not a significant change in creative competencies during the semester $(t(25)=-1.301, p=.205, D=0.23)$. Students' score on the creative competencies scale showed a slight, non-significant decrease from 3.29 at the start of the semester to 3.11 at the end of the semester. Thus, the hypothesis that students' creative competencies would not be impacted was supported.

\subsection{Research Question 3: Did Students' Self- Efficacy for Applying Computational Thinking Increase After Taking the Com- putational Creativity Course?}

Repeated-measures (ANOVA) was used to examine change in selfefficacy across all three time points at which data were collected during the semester. Only students who completed the selfefficacy scale at all three times were included in the analysis, resulting in an analysis sample of 20 participants. Students experienced a significant linear increase in self-efficacy during the semester (Wilks' $\Lambda=.408, F(2,18)=13.050, \mathrm{p}<.001$, partial eta $^{2}=$ $.592)$. This effect is large. On average, students' self-efficacy increased from 54.8 at the start of the semester, to 64.7 in the middle 
of the semester, to 72.9 at the end of the semester. This finding supports the hypothesis that students' self-efficacy would increase during the Computational Creativity course, and it suggests the online Computational Creativity course can be used to increase students' self-efficacy for applying computational thinking in their fields.

\subsection{Research Question 4: How Did Students Feel About the Computational Creativity Course?}

On the whole, students rated the course and the exercises positively. The following three tables provide descriptive statistics based on the ratings students gave to several aspects of the course and the exercises. Ratings pertain to perceived "usefulness," "interestingness," and "effectiveness." Means and standard deviations for all ratings are given in Tables 1-3.

As shown in Table 1, students generally found the CCEs to be useful and interesting. The Exploring exercise was rated as more useful than interesting, but the Storytelling exercise received considerably higher ratings for interestingness than usefulness. Thinking Inside the Box and Everyday Object were rated similarly in terms of usefulness and interestingness.

The means and standard deviations shown in Table 2 reveal that most students found the problem-solving tasks and analysis and reflection questions to be useful. The collaborative format and exercise Lightbulbs were rated as slightly less useful. Table 3 shows the effectiveness ratings of the CCEs as well as the Computational Creativity course as a whole. Students gave slightly higher ratings to the CCEs than the course, but all average ratings were above the "somewhat effective" threshold (i.e., $>3$ out of 5).

\section{Discussion and Conclusions}

Overall, the findings of this study support the hypotheses: Students in the online Computational Creativity course improved their knowledge of computational thinking and experienced an increase in self-efficacy after taking the course. Prior research has shown that the CCEs improve students' computational thinking knowledge and skills when they are completed as part of a CS course, and these findings indicate they can also have a positive impact when implemented in courses that do not have the same elements of a traditional CS curriculum. The positive effects indicate that it is possible for students to learn computational knowledge and skills through an online course that is neither a programming course nor a CS course. This empirical evidence of the effectiveness of such an online course is reassuring as more and more college courses, in CS and other disciplines, are offered entirely online. The generally positive ratings of both the course and the CCEs is promising, especially considering this was the first time the course was offered entirely online.

Consistent with prior studies $[21,25]$ the Computational Creativity course did not change students' creative competencies. Thus, it seems that instruction informed and supported by the computational creativity framework taps into students' existing creative competencies without necessarily growing them. It is yet to be determined whether the effects of the CCEs or the Computational
Creativity course would change if more emphasis were placed on increasing creative competencies alongside learning and selfefficacy. Currently, the creative competencies are reflected in the Creative Objectives of each CCE, but Epstein's [8,9] creative competencies and the scale used to measure them have

Table 1: Ratings of Exercise Usefulness and Interestingness

\begin{tabular}{|l|c|c|c|c|}
\hline & \multicolumn{2}{|c|}{ Usefulness } & \multicolumn{2}{c|}{$\begin{array}{c}\text { Interesting- } \\
\text { ness }\end{array}$} \\
\hline Exercises & Mean & SD & Mean & SD \\
\hline Exploring & 4.89 & 1.25 & 4.67 & 1.24 \\
\hline Thinking Inside the Box & 4.33 & 1.44 & 4.41 & 1.53 \\
\hline Storytelling & 4.48 & 1.19 & 4.89 & 1.09 \\
\hline Everyday Object & 4.56 & 0.85 & 4.52 & 1.16 \\
\hline
\end{tabular}

Note. Response scale was 1 = very unuseful (uninteresting), $2=$ unuseful (uninteresting), 3 = somewhat unuseful (uninteresting), 4 = somewhat useful (interesting), $5=$ useful (interesting), $6=$ very useful (interesting). Statistics are based on responses from the 27 students who completed the post-survey.

Table 2: Ratings of CCE Components

\begin{tabular}{|l|c|c|}
\hline How useful was... & Mean & SD \\
\hline The collaborative group/teamwork format & 4.07 & 1.52 \\
\hline Problem solving tasks & 5.26 & 0.53 \\
\hline Analysis questions & 4.96 & 0.76 \\
\hline Reflection questions & 4.78 & 1.15 \\
\hline Lightbulbs & 4.37 & 1.39 \\
\hline
\end{tabular}

Note. Response scale was $1=$ very unuseful, $2=$ unuseful, $3=$ somewhat unuseful, $4=$ somewhat useful, $5=$ useful, $6=$ very useful. Statistics are based on responses from the 27 students who completed the post-survey.

more to do with one's general habits and tendencies that increase the likelihood one will be creative than any potentially creative actions and ideas generated during individual learning activities like CCEs. For example, one component of Capturing is the practice of recording ideas, thoughts, or solutions in a notebook or journal. Students are required to Capture their ideas and work on the CCEs, but the CCEs and the Computational Creativity course do not explicitly encourage students to make this a more general habit, and it is the general habit of Capturing that is measured by our scale. Therefore, it is possible students use of creativity is changing as they complete CCEs, but not their creative competencies, as outlined by Epstein.

The possibility of impacting students' creative competencies should be explored in future studies. It is possible that a curriculum that explicitly targets creative competencies could increase them and also change the impact the CCEs have on learning and self-efficacy. Future research should also compare online and faceto-face versions of computational thinking courses for non-CS majors. Though the study presented here indicates computational thinking skills can be learned through an online class, it does not address the question of whether online and face-to-face instruction yield different learning outcomes. 
Table 3: Ratings of the Effectiveness of CCEs and the Computational Creativity Course

\begin{tabular}{|c|c|c|}
\hline Question & Mean & SD \\
\hline $\begin{array}{l}\text { How effective do you think the computational creativity exercises in your course were in meeting their objec- } \\
\text { tives? }\end{array}$ & 4.00 & 0.86 \\
\hline $\begin{array}{l}\text { How effective were the computational creativity exercises in preparing you to use computational thinking crea- } \\
\text { tively in your field? }\end{array}$ & 3.64 & 1.10 \\
\hline $\begin{array}{l}\text { How effective were the computational creativity exercises in helping you understand and use computer science } \\
\text { methods and tools in your field? }\end{array}$ & 3.41 & 1.01 \\
\hline $\begin{array}{l}\text { How effective were the computational creativity exercises in giving you ideas about how to think and problem } \\
\text { solve more creatively in your field? }\end{array}$ & 3.96 & 0.84 \\
\hline How effective was the "Computational Creativity" course in meeting its objectives? & 3.78 & 1.39 \\
\hline $\begin{array}{l}\text { How effective was the "Computational Creativity" course in preparing you to use computational thinking crea- } \\
\text { tively in your field? }\end{array}$ & 3.59 & 0.97 \\
\hline $\begin{array}{l}\text { How effective was the "Computational Creativity" course in helping you understand and use computer science } \\
\text { methods and tools in your field? }\end{array}$ & 3.37 & 1.18 \\
\hline $\begin{array}{l}\text { How effective was the "Computational Creativity" course in giving you ideas about how to think and problem } \\
\text { solve more creatively in your field? }\end{array}$ & 3.81 & 1.00 \\
\hline
\end{tabular}

Note. Response scale was 1 = not effective, 2 = neither effective nor ineffective, $3=$ somewhat effective, $4=$ effective, $5=$ very effective. Statistics are based on responses from the 27 students who completed the post-survey.

Additional research that uses stronger quasi-experimental designs is needed in order to determine how mastery of computational thinking skills through this course compares to that of other similar courses.And, it is important that future research examines the possibility of subgroup differences (e.g., men and women, firstyear and advanced students) when teaching computational thinking online. If online computational thinking classes for nonmajors, such as the Computational Creativity course, can effectively build students' computational thinking skills, they could be used to further the goal of introducing a wider range of students to computing and computational thinking.

\section{ACKNOWLEDGMENTS}

This work was partially supported by the National Science Foundation (Grants No. 0829647, 1431874, and 1122956).

\section{REFERENCES}

[1] Merry McDonald, Brian Dorn, and Gary McDonald. 2004. A statistical analysis of student performance in online computer science courses. In Proceedings of the ACM Technical Symposium on Computer Science Education (SIGCSE'04). Norfolk, VA, 71-74.

[2] Robert McCloud. 2004. Does an online course work in computer science?. F. of Computing Sciences in Colleges, 19, 5 (2004), 260-269.

[3] Joseph D. Dumas. 2016. Online vs. face-to-face student performance in an introduction to operating systems course. F. of Computing Sciences in Colleges, 32, 2 (2016), 185-191.

[4] Lynne N. Kennette and Bibia R. Redd. 2015. Instructor presence helps bridge the gap between online and on-campus learning. College Quarterly, 18, 4 (Fall 2015).

[5] Tuan Nguyen. 2015. The effectiveness of online learning: Beyond no significant difference and future horizons. MERLOT f. of Online Learning and Teaching, 11, 2 (Jun. 2015), 309-319.

[6] Tal Soffer and Rafi Nachmias. 2018. Effectiveness of learning in online academic courses compared with face-to-face courses in higher education. 7. of Computer Assisted Learning, online first access (2018), 1-10. doi: 10.1111/jcal.12258

[7] Jenette Wing. 2006. Computational thinking. Commun. of the ACM, 49 (Mar. 2006), 33-35.

[8] Robert Epstein. 1996. Cognition, creativity, and behavior: Selected essays. Praeger, Westport, CT.

[9] Robert Epstein. 2005. Generativity theory and creativity. Theories of creativity. In Theories of Creativity, M.A. Runco and R.S. Albert (Eds.). Hampton Press, Cresskill, NJ.
[10] Albert Bandura. 1977. Self-efficacy: Toward a unifying theory of behavioral change. Psychological Review, 84, 2 (1977), 191-215.

[11] Mingrui Zhang, Eugene Lundak, Chi-Cheng Lin, Tim Gegg-Harrison, and Joan Francioni. 2007. Interdisciplinary application tracks in an undergraduate computer science curriculum. In Proceedings of the ACM Technical Symposium on Computer Science Education (SIGCSE'07). Covington, KY, 425-429.

[12] Zachary Dodds, Ran Libeskind-Hadas, Christine Alvarado, and Geogg Kuenning. 2008. Evaluating a breadth-first CS 1 for scientists. . In Proceedings of the ACM Technical Symposium on Computer Science Education (SIGCSE'08). Portland, OR, 266-270.

[13] Thomas J. Cortina. 2007. An introduction to computer science for non-majors using principles of computation. In Proceedings of the ACM Technical Symposium on Computer Science Education (SIGCSE'07). Covington, KY, 218-222.

[14] Leen-Kiat Soh, et al. 2009. Renaissance computing: An initiative for promoting student participation in computing. In Proceedings of the ACM Technical Symposium on Computer Science Education (SIGCSE'09). Chattanooga, TN, 59-63.

[15] Susanne Hambrusch, Cristoph Hoffmann, John T. Korb, Mark Haugan, and Antony L. Hosking. 2009. A multidisciplinary approach towards computational thinking for science majors. In Proceedings of the ACM Technical Symposium on Computer Science Education (SIGCSE'09). Chattanooga, TN, USA. 183-187.

[16] Hong Qin. 2009. Teaching computational thinking through bioinformatics to biology students. In Proceedings of the ACM Technical Symposium on Computer Science Education (SIGCSE'09). Chattanooga, TN, USA. 188-191.

[17] Betul Czerkawski and Eugene W. Lyman. 2015. Exploring issues about computational thinking in higher education. TechTrends, 59, 2 (Mar./Apr. 2015), 57-65.

[18] John Sweller. 1994. Cognitive load theory, learning difficulty, and instructional design. Learning and Instruction, 4, 4 (1994), 295-312.

[19] Bustra Chowdhury, Austin Cory Bart, and Dennis Kafura. 2018. Analysis of collaborative learning in a computational thinking class. In Proceedings of the ACM Technical Symposium on Computer Science Education (SIGCSE'18). Baltimore, MD, 143-148.

[20] Leen-Kiat Soh, Duane F. Shell, Elizabeth Ingraham, Stephen Ramsay, and Brian Moore. 2015. Learning through computational creativity. Commun. ACM, 58, 8 (Aug. 2015), 33-35.

[21] Duane F. Shell., Leen-Kiat Soh, Abraham E. Flanigan, Markeya S. Peteranetz, and Elizabeth Ingraham. 2017. Improving students' learning and achievement in CS classrooms through computational creativity exercises that integrate computational and creative thinking. In Proceedings of the ACM Technical Symposium on Computer Science Education (SIGCSE'17). Seattle, WA, 543-548.

[22] L. Dee Miller, Leen-Kiat Soh, Vlad Chiriacescu, Elizabeth Ingraham, Duane F. Shell, and Melissa Patternson Hazley. 2013. Improving learning of computational thinking using creative thinking exercises in cs-1 computer science courses. In Proceedings of the $43^{\text {th }}$ Annual Frontiers in Education Conference (FIE'13). Oklahoma City, OK, 1426-1432.

[23] L. Dee Miller, Leen-Kiat Soh, and Duane F. Shell. 2014. Integrating computation$\mathrm{al}$ and creative thinking to improve learning and performance in CS1. In Proceedings of the ACM Technical Symposium on Computer Science Education (SIGCSE'14). Atlanta, GA, 475-480.

[24] Alex Ruthmann, Jesse M. Heines, Gena R. Greher, Paul Laidler, and Charles 
Saulters, II. 2010. Teaching computational thinking through musical live coding in Scratch. In Proceedings of the ACM Technical Symposium on Computer Science Education (SIGCSE'10). Milwaukee, WI, 351-355.

[25] Markeya S. Peteranetz, Shiyuan Wang, Duane F. Shell, Abraham E. Flanigan, and Leen-Kiat Soh. 2018. Examining the impact of computational creativity exercises on college computer science students' learning, achievement, selfefficacy, and creativity. In Proceedings of the ACM Technical Symposium on Com puter Science Education (SIGCSE'18). Baltimore, MD, 155-160.

[26] Duane F. Shell, Melissa Patterson Hazley, Leen-Kiat Soh, L. Dee Miller, Vlad Chiriacescu, and Elizabeth Ingraham. 2014. Improving learning of computational thinking using computational creativity exercises in a college CS1 computer science course for engineers. In Proceedings of the $44^{\text {th }}$ Annual Frontiers in Education Conference (FIE'13). Madrid, Spain, 3029-3035.

[27] Markeya S. Peteranetz, Abraham E., Flanigan, Duane F. Shell, and Leen-Kiat Soh. 2017. Computational creativity exercises: An avenue for promoting learning in computer science, IEEE Transactions on Education, 60, 4 (Oct. 2017), 305-313. DOI: $10.1109 /$ TE.2017.2705152
[28] Markeya S. Peteranetz, Abraham E. Flanigan, Duane F. Shell, and Leen-Kiat Soh 2018. Helping engineering students learn in introductory computer science (CS1) using computational creativity exercises (CCEs). IEEE Transactions on Education, advance online publication, (2018), 1-9. DOI: 10.1109/TE.2018.2804350

[29] Robert. Epstein, Steven M. Schmidt, and Regina Warfel. 2008. Measuring and training creative competencies: Validation of a new test. Creativity Research 7 . 20, 7-12.

[30] Duane F. Shell, Leen-Kiat Soh, Abraham E. Flanigan, and Markeya S. Peteranetz. 2016. Students' initial course motivation and their achievement and retention in college CS1 courses. In Proceedings of the ACM Technical Symposium on Computer Science Education (SIGCSE'16). Memphis, TN, 639-644. 